\title{
JUVENTUDES, COLETIVOS E POLÍTICAS PÚBLICAS EM SERGIPE
}

\author{
FRANK MARCON ${ }^{1}$ \\ LETÍCIA OlIVEIRA FEIJÃo GALVÃO
}

\begin{abstract}
RESUMO
A proposta deste artigo é analisamos as políticas públicas voltadas às juventudes no estado de Sergipe e a correlação destas com a participação política juvenil a partir de suas formas de auto-organização através de coletivos. Partimos da revisão bibliográfica acerca do tema Juventudes, destacamos a ascensão e caracterização das Políticas Públicas destinadas a esse segmento social, propondo uma discussão sobre o estado da arte dos estudos sobre juventudes no Brasil e particularmente em Sergipe. Tal bibliografia comporta questões como 0 que é juventude, como esta é entendida enquanto categoria social, qual sua relação com a elaboração de políticas públicas e como essas duas temáticas se interseccionam. Em um outro momento, apresentamos e analisamos alguns dados sobre as políticas de governo do estado de Sergipe e dos munícipios, bem como sobre as formas de atuação política das juventudes através dos coletivos, intensamente implicados por práticas de interesse comum associados ao lazer, a criatividade e a cultura.
\end{abstract}

\section{PALAVRAS-CHAVE \\ Juventudes; Políticas públicas; Coletivos juvenis; Sergipe.}

\section{YOUTH, COLLECTIVES AND PUBLIC POLICIES IN SERGIPE}

\begin{abstract}
The purpose of this article is to analyze the public policies aimed at youth in the state of Sergipe and their correlation with youth's political participation based on their forms of self-organization through collectives. We started from the literature review on the topic of Youth, highlighting the rise and characterization of Public Policies aimed at this social segment, proposing a discussion on the "state of the art" of youth studies in Brazil and particularly in the state of Sergipe. Such bibliography includes questions such as: What is youth, how it is understood as a social category, what is its relationship with the elaboration of public policies and how these two themes intersect with each other. In another moment, we present and analyze some data on government policies in the state of Sergipe and its municipalities, as well as on the forms of political action of youth through collectives, intensely involved by common interest practices associated with leisure, creativity, and culture.
\end{abstract}

\section{KEYWORDS}

Youths; Public policy; Youth collectives; Sergipe.

\section{JEUNESSE, COLLECTIFS ET POLITIQUES PUBLIQUES DANS SERGIPE}

\section{RÉSUMÉ}

Le but de cet article est d'analyser les politiques publiques destinées aux jeunes dans l'état de Sergipe et leur corrélation avec la participation politique des jeunes à partir de leurs formes d'auto-organisation à travers des

\footnotetext{
${ }^{1}$ Doutor em Antropologia. Docente do Departamento de Ciências Sociais da UFS. Coordenador do Grupo de Estudos Culturais, Identidades e Relações Interétnicas. Email: marconfrank@hotmail.com.

${ }^{2}$ Graduada em Ciências Sociais (UFS) e mestranda em Sociologia (PPGS/UFS). É membra do Grupo de Estudos Culturais, Identidades e Relações Interétnicas. Email: leticiaofg@gmail.com.
} 
collectifs sociaux. Nous sommes partis de la revue de la littérature sur le thème de la jeunesse, mettant en évidence la montée et la caractérisation des politiques publiques visant ce segment social, proposant une discussion sur l'état de l'art des études sur la jeunesse au Brésil, notamment dans l'état de Sergipe. Une telle bibliographie comprend des questions telles que qu'est-ce que la jeunesse, comment elle est comprise en tant que catégorie sociale, quelle est sa relation avec l'élaboration des politiques publiques et comment ces deux thèmes se recoupent. Dans un autre moment, nous présentons et analysons quelques données sur les politiques gouvernementales dans l'état de Sergipe et leur municipalités, ainsi que sur les formes d'action politique des jeunes à travers des collectifs, intensément impliqués par des pratiques d'intérêt commun associées aux loisirs, à la créativité et à la culture.

\title{
MOTS-CLÉS \\ Jeunesse; Politiques publiques; Collectifs de jeunes; Sergipe.
}

\section{JUVENTUDES, COLECTIVOS Y POLITICAS PÚBLICAS EN SERGIPE}

\begin{abstract}
RESUMEN
El propósito de este artículo es analizar las políticas públicas dirigidas a la juventud en el estado de Sergipe y su correlación con la participación política juvenil desde sus formas de autoorganización a través de colectivos sociales. Partimos de la revisión de la literatura sobre el tema Juventud, destacando el surgimiento y la caracterización de las Políticas Públicas dirigidas a este segmento social, proponiendo una discusión sobre el estado del arte de los estudios de la juventud en Brasil y particularmente en Sergipe. Esta bibliografía incluye preguntas como: qué es la juventud, como esta se entiende como categoría social, cuál es su relación con la elaboración de políticas públicas y cómo se cruzan estos dos temas. En otro momento, presentamos y analizamos algunos datos sobre las políticas gubernamentales en el estado de Sergipe y sus municipios, así como sobre las formas de acción política de la juventud a través de colectivos, intensamente involucrados por prácticas de interés común asociadas al ocio, la creatividad y la cultura.
\end{abstract}

\section{PALABRAS-CLAVE}

Juventudes; Políticas públicas; Colectivos juveniles; Sergipe. 


\section{INTRODUÇÃO}

Neste artigo, analisamos as políticas públicas voltadas às juventudes no estado de Sergipe e a correlação destas com a participação política juvenil a partir de suas formas de auto-organização através de coletivos. Durante a condução das pesquisas empíricas que deram origem a este texto, buscamos dialogar com representantes do poder público do governo do estado e dos governos municipais de Sergipe, além de representantes de alguns dos coletivos juvenis, como definiremos a seguir ${ }^{3}$.

Como visto por Campos e Sarrouy (2020), o diferencial entre o fazer político da juventude do tempo presente e o das gerações anteriores se dá por meio de uma "gradual fragmentação e individualização da ação política" (CAMPOS; SARROUY, 2020, p. 25), que pode ser observada em fenômenos no âmbito da micropolítica (como as life politics, ou políticas de vida). Condutas individuais, relacionadas a estilos de vida, passam a ser tão importantes para estas juventudes quanto posicionamentos políticos tradicionais entendidos pelo viés da participação política partidária e da militância ideologizada - o eram para as gerações passadas, como esclareceremos no decorrer do artigo. Além disso, como observam os autores citados, a utilização de recursos estéticos aliados a manifestações políticas, mergulhando na esfera da criatividade, se tornou um elemento distintivo geracional das juventudes contemporâneas.

É importante salientar que as juventudes não se limitam apenas à manifestação político-ideológica por meio de ações individuais. A partir de fenômenos como as greves estudantis ocorridas em diversos países devido às mudanças climáticas, e, no Brasil, as manifestações de junho de 2013 e as ocupações às escolas do ensino público em 2016, é possível exemplificar diferentes movimentos de reivindicação ativa e coletiva por direitos, que ocorreram nos últimos anos, e que se caracterizaram pelo uso das tecnologias digitais, pela ocupação do espaço público, pela plasticidade, pela profusão de pautas e pela autonomia. Estes movimentos devem ser considerados por mostrarem as novas formas de as juventudes reivindicarem o que entendem por participação política e cidadania, muitas vezes por meio de recursos simbólicos específicos associados aos seus estilos de vida e a atuação política direta.

O objetivo geral deste artigo é analisar em que condições se encontram as políticas públicas para as juventudes no estado de Sergipe, por um lado, e, por outro lado, como os

\footnotetext{
${ }^{3}$ Este artigo foi escrito a partir da literatura e do material empírico coletado no bojo de outras duas pesquisas do autor e da autora: o projeto de pesquisa "Juventudes, estilos de vida e sentidos de transição para a vida adulta: protagonismos versus precariedades", PIBIC/UFS, 2019, coordenado pelo autor, e o trabalho de conclusão de curso da autora intitulado "Juventudes e políticas públicas na grande Aracaju: os coletivos MUDE e Socorreria Arte Urbana" (GALVÃO, 2021).
} 
jovens articulados em forma de coletivos reivindicam e problematizam a garantia destas políticas, analisando tal disputa a partir do contraste entre os modos de fazer e entender o político por parte do poder público e por parte dos coletivos. A ênfase que damos aqui aos coletivos envolvidos com o campo cultural está diretamente relacionado ao enfoque criativo deste ativismo, que se implica politicamente pela ação estética, pela comunicação digital e pela expressão contestadora na cena pública, mesmo quando não estão diretamente organizados em função de um ativismo voltado para o campo das expressões artísticas.

A seguir, partimos da revisão bibliográfica acerca do tema juventudes, particularmente em Sergipe, e destacamos a ascensão e caracterização das Políticas Públicas destinadas a esse segmento social, propondo uma discussão sobre seu estado da arte e contextualizando seu processo de institucionalização. Apresentamos algumas características das políticas de governo do estado de Sergipe e seus munícipios e, em um segundo momento, acrescentamos a análise sobre os coletivos de juventudes como formas de autoorganização e atuação política, destacando as diferenças entre a atuação da administração pública e dos coletivos juvenis. Por fim, acessamos as percepções e o modo de atuação dos coletivos através de entrevistas, das redes sociais (Instagram, Facebook, WhatsApp) e da bibliografia que tem estudado o tema no estado de Sergipe e, a partir daí, dialogamos com as reflexões teóricas recentes sobre coletivos juvenis e participação política ${ }^{4}$.

\section{AS POLÍTICAS PÚBLICAS PARA JUVENTUDES NO BRASIL E EM SERGIPE}

As primeiras concepções consensuais que visaram compreender as necessidades e particularidades das juventudes em uma perspectiva global se deram a partir de 1985, quando a Organização das Nações Unidas (ONU) declarou o Ano Mundial da Juventude, com o lema "Participação, Desenvolvimento e Paz" (ONU, 1985). Por meio desta iniciativa, a ONU buscou reconhecer a importância de os jovens articularem o futuro da humanidade (ONU, 1985), ressaltando a relevância de sua participação ativa e direta a nível local, regional e nacional. Pode-se considerar, portanto, o Ano Mundial da Juventude como um ponto de partida para a reivindicação de políticas de juventude em uma escala global - o que significou o reconhecimento do ser jovem e da juventude como condição etária e como categoria social de direitos e colocou o tema das juventudes nas agendas políticas de muitos países e tratados internacionais.

\footnotetext{
${ }^{4}$ O material empírico que serviu de base para a escrita deste artigo é o conjunto de 15 entrevistas que realizamos em 2020, com representantes de secretarias, coordenadorias ou diretorias municipais e estadual das juventudes, no âmbito do de pesquisa PIBIC/UFS, bem como, algumas das entrevistas com as lideranças dos coletivos e a pesquisa na internet foram realizadas originalmente para o TCC "Juventudes e políticas públicas na grande Aracaju: os coletivos MUDE e Socorreria Arte Urbana" (GALVÃO, 2021), ambos citados na nota anterior.
} 
No Brasil, segundo Sposito e Carrano (2003), as políticas públicas voltadas especificamente à juventude surgem a partir da década de 1990. Antes disso, as políticas existentes que atingiam os jovens estavam direcionadas transversalmente às demais faixas etárias, por abranger outras modalidades de recortes sociais, não sendo a juventude, portanto, uma condição específica ou os jovens um grupo específico objeto de tais políticas. Os autores, no artigo "Juventudes e Políticas Públicas no Brasil" (CARRANO; SPOSITO, 2003), comentam que grande parte das políticas voltadas à juventude a partir do período mencionado se posicionavam enquanto facilitadoras do processo de integração dos jovens ao mundo adulto, tendo como foco jovens em situações de vulnerabilidade.

Em contraponto às proposições da ONU, é possível perceber um atraso na elaboração e no debate sobre políticas públicas para a juventude no Brasil. Como posto acima, as primeiras discussões sobre políticas para juventudes surgiram no Brasil apenas na década seguinte às primeiras mobilizações internacionais. Não obstante, por vários anos e governos, se apoiaram em concepções que visavam a resolução de "problemas" sociais, sugerindo que os jovens eram um problema social ou que tal fase da vida era experimentada de forma problemática, sendo comum adotar o conceito de "risco social" (SPOSITO; CARRANO, 2003) ao se referir a determinados contextos vivenciados pelas juventudes.

Helena Abramo (1997), no artigo "Tematização Social da Juventude no Brasil", problematiza a forma como a juventude foi tematizada nas iniciativas voltadas à mesma durante o século XX. Para a autora, houve uma dificuldade por parte do poder público em compreender os jovens enquanto sujeitos (ABRAMO, 1997), na linha de que jovens deveriam ser tutelados, por estarem em desenvolvimento ou pela falta de maturidade. Nesse sentido, a promulgação do Estatuto da Criança e do Adolescente (ECA), em 1990, foi um marco no avanço de políticas sociais voltadas à infância e à juventude, bem como um avanço na maneira de o Estado enxergar as juventudes, embora a maior parte do Estatuto seja dedicada ao tema das infrações e em como tutelar os adolescentes infratores. A partir do Estatuto, programas foram criados, apoiados na noção de cidadania, noção esta que visa proteger integralmente crianças e jovens.

Segundo Diógenes (2009), em virtude do Estatuto,

"A natureza meramente punitiva, disciplinadora, que regia o código de menores (Lei n. 6.679 , de 1979) e que se referendava na ideia de "situação irregular", assume outra perspectiva e considera que o adolescente em conflito com a Lei encontra-se em "situação peculiar de desenvolvimento" e, consequentemente, como sujeito capaz de ressignifcar suas experiências e transmudá-las" (DIÓGENES, 2009, p. 272).

Posteriormente, entre os anos de 1999 e 2002, no segundo mandato do expresidente Fernando Henrique Cardoso, surge um número consideravelmente maior de programas voltados à juventude em âmbito federal, com iniciativas voltadas ao esporte, à 
qualificação profissional, à educação e ao voluntariado5. Sposito e Carrano (2003) observam que tais programas, todavia, não constituíam uma totalidade orgânica no que diz respeito ao entendimento das políticas para as juventudes, mas se tornaram indicativos de uma maior consciência por parte do poder público de que a juventude é uma categoria social que demanda atenção específica e que ultrapassa a condição etária da adolescência, predisposta pelo limite da idade de responsabilidade civil no ECA.

Partindo do final dos anos 1990 e do início da década seguinte, como mencionam Tommasi e Corrochano (2020, p. 362), os jovens "são incentivados a elaborar e realizar projetos de intervenção para solucionar problemas sociais. A imagem do jovem como protagonista, agente de mudança, é contraposta àquela do jovem como problema social". Como mencionam Sposito e Carrano (2003, p. 31), os "dois conceitos vigoraram em documentos de órgãos do governo federal e organizações não-governamentais, principalmente quando referentes a projetos e programas fortemente focados na juventude: protagonismo juvenil e jovens em situação de risco social".

A noção de protagonismo juvenil, segundo Bhogossian e Minayo (2009), vem sendo apropriada e adaptada de diversas formas pelas iniciativas voltadas à juventude. O termo surge na década de 1990, enquanto "pilar das inovações postuladas na reforma curricular do ensino médio" (FERRETTI apud BHOGOSSIAN; MINAYO, 2009, p. 416), enquadrando-se enquanto proposta político-pedagógica direcionada à "ação cidadã". A ideia central do protagonismo juvenil baseia-se na "criação de espaços e mecanismos de escuta e participação dos jovens em situações reais na escola, na comunidade e na vida social, tendo em vista tanto a transformação social como sua formação integral" (COSTA apud BHOGOSSIAN; MINAYO, 2009, p. 416).

Os autores enfatizam que, com o passar dos anos, o protagonismo juvenil ganhou proporções maiores ao alcançar órgãos internacionais, principalmente quando vinculado a uma ideia de empoderamento dos jovens. Contudo, como afirmam Bhogossian e Minayo (2009), determinadas interpretações do protagonismo juvenil acabam por simplificá-lo, tornando-o mais adaptativo do que problematizador e caminhando para uma despolitização do conceito. Para os autores, tais interpretações acabam por responsabilizar unicamente os jovens pelos problemas que enfrentam, individualizando questões de ordem política. Tendo isso em vista, é importante pontuar que a adoção da ideia de protagonismo juvenil em políticas de juventude deve perpassar princípios que considerem tanto a capacidade dos

\footnotetext{
${ }^{5}$ Cabe levantar que o governo Fernando Henrique Cardoso via o voluntariado como uma maneira de envolver os jovens nas questões sociais, chamando-os (como parte da sociedade civil) a intervirem no social, embora gratuitamente; o Programa Universidade Solidária pode ser mencionado como um exemplo de tal abordagem, apresentando nestes programas o modelo predominante de "protagonismo" vislumbrado por tal gestão.
} 
jovens de intervirem em suas realidades quanto a necessidade de que Estado e a sociedade atendam a certas garantias de direitos e demandas dos jovens, o que não quer dizer que ocorram de fato.

Silva (2020) enfatiza que o governo Lula, entre os anos de 2003 e 2010, ocupou um papel importante no desenvolvimento e na implementação de políticas para a juventude, principalmente pela institucionalização da participação dos jovens na sua elaboração, bem como pela definição de normas legais a nível federal e pela orientação de diretrizes e programas de financiamento nacionais, o que constituiu um importante reconhecimento público de estado sobre a categoria social. Cabe mencionar que, no ano de 2003, foi realizada a pesquisa Perfil da Juventude Brasileira por meio do projeto Juventude/Instituto Cidadania, em parceria com o Instituto de Hospitalidade e o Sebrae. A pesquisa foi conduzida por meio de um estudo quantitativo abarcando jovens de áreas urbanas e rurais de todo o Brasil, de 15 a 24 anos, de ambos os sexos. Segundo Diógenes (2009, p. 275), a pesquisa destacou que "as políticas públicas deveriam considerar não somente a dimensão formativa da juventude, mas também aquela referente à experimentação e à participação" e todo um debate sobre outras dimensões da vida dos jovens para além da escolarização, do trabalho e da violência passou a ser recorrente na primeira década do século XXI.

Em 2005, é criado o Conselho Nacional de Juventude (Conjuve), por meio da Lei 11.129, que também instituiu a Secretaria Nacional de Juventude, em 2003, e o Programa Nacional de Inclusão de Jovens (Projovem). As atribuições do Conjuve, desde então, segundo o Governo Federal, são "formular e propor diretrizes voltadas para as políticas públicas de juventude, desenvolver estudos e pesquisas sobre a realidade socioeconômica dos jovens e promover o intercâmbio entre as organizações juvenis nacionais e internacionais" (BRASIL, 2020). Tais marcos legais levaram para dentro do estado o debate conceitual sobre as juventudes e as agendas de grupos já organizados ou daqueles que passaram a se ver como tais, desde então.

O governo Dilma, abarcando os anos de 2011 a 2016, também apresentou iniciativas atendendo as progressivas demandas das juventudes. A promulgação do Estatuto da Juventude, em 2013 - que levara dez anos sendo gestado, debatido e negociado representou um avanço na implementação das políticas dirigidas aos jovens pois, por meio deste, foram estabelecidas diretrizes sobre os direitos e como devem ser constituídas e elaboradas as políticas para este público também a nível de estados e municípios. Princípios como a autonomia e emancipação, participação social e política, e, antes de tudo, o reconhecimento dos jovens como sujeitos de direitos foram contemplados na Lei do referido Estatuto (BRASIL, 2013). Contudo, Silva (2020) percebe que, com o período de instabilidade política que se deu a partir de 2016, as pautas da juventude e o financiamento de tais políticas foram profundamente afetadas e, apesar das normativas, do reconhecimento e das 
orientações, de lá para cá pouco se avançou no alcance dos objetivos propostos, da disponibilidade de recursos e da efetiva estruturação e execução de tais políticas.

Nesse contexto, é pertinente observar que, mesmo que estejamos diante de um cenário que implica entender a consolidação de tais políticas em um contexto mais amplo, a aprovação do Estatuto da Juventude definiu diretrizes nacionais para a estruturação e organização normativa das políticas para as juventudes nos estados e municípios. Neste sentido, consideramos que a particularidade do seu desenvolvimento nos âmbitos estadual e municipal são diversas, e dependem das dinâmicas sociais, econômicas e políticas regionais, embora devam ser orientadas pelo guarda-chuvas das diretrizes gerais.

No Estado de Sergipe, como na maior parte dos estados da federação, as políticas públicas voltadas à juventude são ainda mais recentes. Cavalcante (2010) observa que no período de 2002 a 2006 foi possível identificar algumas iniciativas segmentadas, como parcerias com a Universidade Tiradentes, instituição privada, para ampliar o acesso dos jovens ao ensino superior. Entretanto, como observa a autora, "o Governo Estadual atendeu de forma parcial, fragmentada, as demandas das juventudes e não criou canais de diálogo com os movimentos juvenis e sociais" (CAVALCANTE, 2010, p. 94). A ideia predominante em tal caso foi quase que exclusivamente o da ampliação das possibilidades de continuidade da escolarização e qualificação para o trabalho, sem avançar com o debate sobre a constituição de marcos legais para institucionalização de direitos e garantias das juventudes do estado.

No entanto, é importante mencionar, no contexto das poucas iniciativas políticas no estado, a realização da pesquisa "Juventudes Sergipanas" por Bernard Charlot (2006), que se tornou o primeiro estudo abrangente e de fôlego sobre as juventudes em Sergipe. Tal pesquisa dedicou-se a mapear e conceituar as juventudes do estado por meio de estudos quantitativos e qualitativos, a partir de questionários aplicados à jovens na rede escolar do estado. Dessa forma, como demonstra a publicação, seu intuito foi traçar o perfil dos "jovens sergipanos", abrangendo áreas como educação, trabalho e estilos de vida, criando um banco de dados que se tornou um diagnóstico de referência nos estudos sobre as juventudes em Sergipe.

A partir do ano de 2007, no início e durante a gestão do ex-governador Marcelo Déda (que durou até 2011), pôde-se notar um maior número de programas e iniciativas voltados à juventude por parte do Governo Estadual. Como menciona Cavalcante (2010), o então governador incluiu já em sua proposta de governo o compromisso com a elaboração de políticas de juventudes, reconhecendo os jovens enquanto seres de direitos especiais devido à sua condição social. Cabe mencionar alguns objetivos destas políticas, como a) a implementação de políticas educacionais, b) de inclusão da juventude no mercado de trabalho e c) uma maior valorização do acesso aos jovens por meio da cultura. Na mesma gestão, vale destacar a criação da Coordenadoria Estadual de Juventude (CEJU) e a 
realização da I Conferência Estadual da Juventude e do I Seminário de Políticas Públicas de Juventude, ambos no ano de 2007. É importante mencionar tais eventos pois, segundo Silva (2020), "é a partir dos resultados alcançados por meio das conferências que surgem os programas e projetos destinados à sociedade" (SILVA, 2020, p. 38). A dinamização e a convergência do debate público sobre as condições sociais e de vida das juventudes passa a envolver Estado e sociedade, incluindo, principalmente, a participação dos próprios jovens.

Durante o mandato do sucessor de Marcelo Déda, o ex-governador Jackson Barreto (de 2013 a 2018), foi criada a Secretaria de Juventude e Esporte (SEJESP) por meio da Lei 4.371, em 2013. Posteriormente, logo a seguir, em janeiro de 2014, foi criado o Conselho Estadual de Políticas Públicas de Juventude (CONEJUVE) através da Lei 7.815, sendo este, segundo as normas atuais, o órgão político legítimo, oficial e independente de representação dos jovens junto ao governo do Estado.

No conjunto das ações governamentais da secretaria responsável pela pasta da juventude, foram implantados, no ano de 2017, os programas como Família na Рraça, responsável por incentivar atividades de lazer, e as Casas da Juventude, cujo intuito é de "promover o desenvolvimento de maneira integral aos jovens entre 15 e 29 anos que estejam em situação de vulnerabilidade social, no intuito de desenvolver políticas públicas que fortaleçam sua autonomia" (SILVA, 2020, p. 40). De acordo com Silva (2020), as Casas da Juventude foram criadas para elaborar propostas de geração de emprego, lazer, educação, cultura, saúde e direitos humanos por meio de palestras e oficinas. A autora destaca que dezessete municípios sergipanos aderiram a esta iniciativa, embora a partir das entrevistas que realizamos com gestores e representantes dos conselhos da juventude e coletivos, em 2020, foi possível percebermos que poucas destas casas têm conseguido se manter em atividade.

Com as mudanças de rumo político ocorridas no Brasil, a partir do impeachment da presidenta Dilma Rousseff, em 2016, a crise política, social e econômica afetou organicamente e financeiramente as inúmeras políticas públicas dirigidas a grupos sociais específicos como o das juventudes, bem como afetou também seu financiamento no âmbito dos estados da federação. Em Sergipe, na gestão do atual governador Belivaldo Chagas (iniciada em 2018), as políticas de juventude passaram a se concentrar na mesma secretaria encarregada de gerenciar a Educação, o Esporte e o Lazer. De acordo com Silva (2020), a ênfase da proposta da gestão de Belivaldo Chagas, no que diz respeito ao tema das juventudes, foi relacionar a juventude ao eixo da cultura e do esporte. De modo geral, notase que no presente, em Sergipe, não há uma estrutura esquematizada, com orçamento público significativo e um investimento direto nessa área, que possa ser considerado algo sistemático, abrangente e eficaz (ENTREVISTA COM HORA, 2020). 
O tema trabalho/emprego/renda esteve no foco da elaboração das políticas públicas para a juventude no Brasil, assim como em Sergipe, sendo comum a implementação de programas que visassem a inclusão dos jovens no mercado de trabalho, a partir de programas como o Jovem Aprendiz, a nível federal, e suas aplicações locais. Contudo, como observam Tommasi e Corrochano (2020), é insuficiente incentivar a capacitação dos jovens quando a realidade com a qual eles se deparam é um mercado de poucas oportunidades. É pertinente ressaltar que não estamos tratando do alcance e da eficácia das políticas públicas nestas áreas, mas apresentando um quadro síntese sobre quais áreas têm sido ressaltadas como prioritárias pelos gestores das políticas públicas para as juventudes em Sergipe.

Em 12 em agosto de 2020 (conhecido como Dia Internacional de Juventude a partir de resolução da ONU em 1999), o Conselho da Juventude do Estado de Sergipe (CONEJUVE) realizou um encontro público em uma rede social na internet, apresentando para o debate os resultados do diagnóstico "Retratos da Juventude", elaborado pelo próprios conselheiros, cujos objetivos, segundo eles, foram "conhecer as vivências, realidades e opiniões", "influenciar a institucionalização da política de juventude" e "produzir evidências para subsidiar políticas públicas"6. A realização do Diagnóstico se deu por meio de um questionário online, durante os primeiros meses de 2020, contemplando cerca de 9.107 jovens, de 46 municípios do Estado. Dessa forma, o diagnóstico realizado pelo CONEJUVE foi uma iniciativa que visou mapear as múltiplas realidades experienciadas pela juventude em Sergipe, representando um avanço na reivindicação por políticas públicas, ao produzir sua própria leitura sobre as condições e demandas das juventudes no estado.

Entretanto, é importante ressaltar que a realização do referido diagnóstico "Retratos da Juventude" ocorreu sete anos após a promulgação do Estatuto da Juventude, bem como trinta anos após a promulgação do Estatuto da Criança e do Adolescente. Associando estas afirmações ao fato de que a grande maioria das secretarias e coordenadorias de juventude no estado não possui verba própria (GALVÃO; SANTANA; OLIVEIRA, 2020) e, em diversos casos, sequer há setores e políticas voltadas em específico aos jovens, é possível perceber que as iniciativas em prol da juventude no estado de Sergipe caminham a passos lentos, com avanços e recuos. Embora o Conselho Estadual da Juventude, criado em 2014, seja um importante marco da representação, da resistência e da insistência sobre sua importância, assim como as juventudes também se articulem muitas vezes à sua própria maneira para reivindicar o que entendem por seus interesses e direitos e nem sempre aceitem a condição passiva de aguardarem o apoio governamental.

\footnotetext{
${ }^{6}$ O Diagnóstico foi apresentado por meio de transmissão ao vivo pelo Facebook. As informações sobre a pesquisa estão disponíveis em: https://www.facebook.com/conejuvse/videos/304089914146725.
} 


\section{JUVENTUDES E COLETIVOS: NOVAS FORMAS DE PARTICIPAÇÃO POLÍTICA}

São crescentes os estudos sobre novas formas de ação política por parte das juventudes no Brasil e no mundo (AUGUSTO, 2008; MARCON, 2018; CAMPOS; SARROUY, 2020; BHOGOSSIAN; MINAYO, 2009). Como apresentam Bhogossian e Minayo (2009), no artigo "Revisão Sistemática sobre Juventude e Participação", há uma desagregação, distanciamento e desinteresse por parte dos jovens diante das formas organicistas e convencionais de fazer política, ao mesmo tempo em que gerações anteriores ainda sustentam concepções institucionalizadas e hierárquicas sobre participação política. Tais concepções também costumam ser reverberadas por veículos de mídia, como observam Campos e Sarrouy (2020).

Estes dois fatores (a desagregação dos jovens da política convencional e o entendimento das gerações mais velhas sobre o que é, ou deveria ser, a participação política) geram uma série de conflitos intergeracionais que afastam os jovens da arena política consagrada pela dimensão orgânica, partidária e governamental. Silva (2020), em sua dissertação de mestrado sobre juventudes, hip-hop e políticas públicas na Grande Aracaju, possibilita visualizar os pontos de vista das gerações anteriores: "em todas as entrevistas, os gestores públicos compararam as juventudes do presente com as do passado, abordando que atualmente há um desinteresse na ascensão individual que definem como ligadas principalmente a educação e a profissão" (SILVA, 2020, p. 45). Contudo, isso não significa que os jovens se afastem do fazer político de fato, nem que sejam unanimemente entendidos como "desinteressados".

Campos e Sarrouy (2020) mostram que

"Esta visão pessimista é contrariada por uma linha de pesquisa que recupera o papel dos jovens como sujeitos políticos relevantes, entendendo inclusive a sua ação como uma expressão de dinamismo e um indicador de saudabilidade do regime democrático. A sua postura, umas vezes apontada como apática, outras como apolítica, não deixa de ser profundamente política, na medida em que revela uma atitude perante as instituições e os seus atores que redunda, tantas vezes, em vias diversas para a participação" (CAMPOS; SARROUY, 2020, p. 36).

Nuno Miguel Augusto (2008), no artigo "A juventude e a(s) política(s): Desinstitucionalização e Individualização", discute a questão da desagregação dos jovens das formas tradicionais de participação política, como a filiação a partidos. Рara o autor, tal fenômeno (em Portugal) ocorria motivado pela crescente desconfiança da juventude frente às práticas institucionalizadas da política, bem como há um processo de individualização nas pautas contempladas pelas juventudes. Entretanto, tal individualização não deve ser confundida com uma despolitização, pois neste mesmo cenário cresce o chamado associativismo juvenil. Nesta forma de ação política, ocorre uma segmentação das pautas juvenis de forma não-partidária. Augusto (2008) destaca, principalmente, o âmbito do lazer 
como catalisador destas novas formas de associativismo. Nós reforçamos que, para além do lazer, a criatividade, o conhecimento, a informação, a comunicação, a saúde, as pautas identitárias e o meio ambiente, se somam ao esporte, à cultura, à escolarização e ao trabalho como novos campos de envolvimento e atuação dos jovens, a partir das quais eles dão relevância as suas vidas.

Honwana (2014) sustenta uma argumentação similar:

"Os jovens já estão desenvolvendo formas alternativas para a intervenção social e política, fora de partidos políticos e em organizações da sociedade civil. Eles estabelecem e envolvem-se em associações que desenvolvem acções políticas sem necessidade de filiação partidária. Lutam pela liberdade de expressão nos mundos reais e virtuais; lideram campanhas públicas contra a corrupção e pela boa governação, pelos direitos da mulher, protecção do meio ambiente, entre outros assuntos" (HONWANA, 2014, p. 409).

Dessa forma, proporcionalmente aos essencialismos construídos por gerações anteriores, surgem "novas formas de engajamento em questões políticas e sociais" (BHOGOSSIAN; MINAYO, 2009), que se manifestam através de ativismos por vezes ancorados em "novas linguagens estéticas de produção da informação" (MARCON, 2018), a exemplo das intersecções entre arte e ativismo (DELGADO, 2013), e também focalizados no âmbito da micropolítica, por meio das chamadas "políticas de vida" ou life politics. Estas, em específico, caracterizam-se por ações de ordem individual orientadas a causas específicas, sendo produto de uma realidade mais globalizada e fragmentada (CAMPOS; SARROUY, 2020) quando comparada a conjunturas anteriores.

Campos e Sarrouy (2020), em consonância com os argumentos de Augusto (2008), associam a agência criativa à agência política dos jovens, estendendo-se sobre o papel da criatividade nas novas formas de participação política das juventudes, que por vezes contemplam esferas não associadas ao fazer político por parte das gerações anteriores, como a arte e o lazer. Diógenes (2020), em "Cidade, arte e criação social: novos diagramas de culturas juvenis da periferia", debate as manifestações da juventude para além do trabalho, por meio da produção cultural e artística por jovens periféricos. As discussões levantadas pela autora abrem caminhos para que se possa, além disso, questionar aquelas políticas públicas que entendem o trabalho como única saída aos "problemas sociais" vivenciados pela juventude.

Especificamente no Estado de Sergipe, tanto Marcon e Souza Filho (2013) quanto Silva (2020) destacam a atuação do hip-hop como expressão cultural de demandas e reivindicações políticas por parte da juventude. No artigo "Estilo de vida e atuação política de jovens do hip-hop em Sergipe", Marcon e Souza Filho (2013) discutem sobre as chamadas posses, movimentos formados por pessoas envolvidas no hip-hop que se articulam em torno de princípios comuns (MARCON; SOUZA FILHO, 2013). No caso das duas posses estudadas pelos autores, os princípios articulados por seus atores envolvem reivindicações políticas. 
Estas reivindicações englobam desde melhorias nas comunidades em que os membros das posses vivem até a atuação direta com os jovens das periferias, em busca de associá-los ao "caminho" do hip-hop em contraponto a condutas envolvendo práticas ilícitas.

Segundo Marcon e Souza Filho (2013, p. 530), "a ideia é que unindo forças em torno da posse, eles possam atuar através da metodologia que definem de 'cultural', e na qual dizem se basear para desenvolver seus projetos sociais em comunidades periféricas". Dessa forma, as reivindicações por parte das posses perpassam, simultaneamente, os campos político e cultural visando melhores condições de vida para as juventudes de tais comunidades.

Como visto pelos autores, nos casos estudados por eles, as posses originaram-se fora da esfera política formal, mas, com o passar dos anos e no decorrer das diferentes conjunturas políticas, elas adentraram os espaços da política formal, a exemplo das filiações de algumas de suas lideranças a partidos como o PT e PCdoB. Estas constatações mostram que manifestações de ordem artística e cultural, a exemplo do hip-hop, apresentam grande potencial de luta por direitos das juventudes e envolvimento ambíguo com as práticas da política institucionalizada. Marcon e Souza Filho (2013, p. 519) evidenciam que para além da via partidária e governamental: "deste modo, há um reclamo dessa juventude por políticas públicas que supram suas expectativas, como é expresso através dos discursos ou das plasticidades do hip-hop.".

Silva (2020), por sua vez, discorre sobre a relação entre o hip-hop, enquanto manifestação cultural das juventudes periféricas, e a elaboração de políticas públicas na grande Aracaju. Em uma discussão voltada à problemática das políticas públicas, a autora destaca a importância destas para o empoderamento dos jovens. Mostra, também, que, por muitas vezes não possuírem forças para resistir à exclusão social, os jovens resistem por meio da cultura e do consumo e ressalta a importância de as políticas de juventude lançarem seu olhar a tais temáticas.

Também devem ser mencionados os trabalhos de Almeida Neto (2012), que se aprofunda na atuação política cotidiana dos jovens do bairro Siqueira Campos, em Aracaju; de Silva (2011), que investiga as práticas de ocupação das praças no centro da mesma cidade; bem como os trabalhos de Fusaro (2018), que estuda as dinâmicas de ocupações culturais que reivindicam o direito à cidade; e de Oliveira (2013) que evidencia a atuação dos jovens no festival Rock Sertão no município de Nossa Senhora da Glória (SE). Todas as produções mencionadas evidenciam como o entretenimento, o lazer e as artes, por exemplo, têm se mostrado ambientes de disputas políticas que apontam para reivindicação de usos de lugares e de modos de existência específicos, marcados sobretudo por práticas culturais.

Como visto, as juventudes têm buscado novas formas de participação política que ultrapassam mecanismos partidários e associativos formais. Gohn (2008) aponta que, a partir 
dos anos 1990, os movimentos sociais brasileiros organizaram-se no que alguns teóricos entendem por redes sociais e temáticas. Segundo a autora, a sociedade civil passa a organizar-se levando em conta vínculos sociais comunitários (como questões de gênero, idade e étnico-raciais) (GOHN, 2008), sendo tais vínculos importantes para a formação das referidas redes. Estas categorias em específico - redes sociais e temáticas - são acionadas porque, segundo Gohn (2008, p. 446), "a rede temática tem poder de articulação que extrapola o nível local, atuando da esfera local até a global. As redes sociais são importantes porque nos indicam os vínculos e as alianças existentes nas redes temáticas". Estas redes sociais, por sua vez, são entendidas pela autora como dotadas de um "enraizamento maior com as comunidades locais" (GOHN, 2008, p. 446).

Santos (2019) entende que as formas contemporâneas de organização política das juventudes são distintas dos movimentos sociais clássicos, caracterizados por sua estrutura organizacional verticalizada e burocrática, bem como também são distintos dos movimentos sociais das décadas de 70 e 80 , cujas dimensões eram menos rígidas que as dos movimentos sociais clássicos, mas ainda não eram flexíveis como as dos movimentos que os sucederam (SANTOS, 2019).

Os novíssimos movimentos sociais, segundo Santos (2019),

"São os que emergiram nas manifestações de rua das duas últimas décadas, trazendo consigo novos sujeitos para a esfera pública brasileira. Composto em sua maioria pela juventude, possuem pautas diversas que variam entre a questão de classe, de gênero, de sexualidade e da mobilidade social. Propõem formas de organização que se distanciam das formas anteriores (os clássicos e novos movimentos sociais) e se aproximam mais dos ideais libertários, tendo os coletivos como as formas mais usuais de organização e articulação" (SANTOS, 2019, p. 224).

Santos (2019) também traz reflexões sobre o caráter de "novo" atribuído às juventudes na arena política, especialmente quando se refere às práticas dos organizadores dos saraus de poesia organizados na cidade de Salvador, objetos de pesquisa do autor. Santos (2019) aponta que, ainda que tais jovens tenham recentemente passado a ocupar lugares políticos, suas demandas não são tão novas assim. O autor indaga: "será que os sujeitos que são novos na cena ou as teorias e metodologias hegemônicas até então utilizadas é que não permitiam perceber esses sujeitos sociais?" (SANTOS, 2019, p. 211).

Além das mudanças contextuais na situação dos movimentos sociais brasileiros mencionadas acima, Gohn (2013) aponta para uma mudança também nas formas de associativismo juvenil em específico. Segundo a autora, "as diferenças passam pelos campos tratados, pelos repertórios, formas de comunicação, identidades criadas, pertencimentos de classe e sociocultural e as formas como aproveitam as oportunidades políticas que surgem" (GOHN, 2013, p. 207). Augusto (2008, p. 169) percebe que associações ligadas ao voluntariado e ao lazer "transformaram-se nos principais espaços de participação dos jovens, retirando centralidade às lógicas institucionalmente definidas e reforçando a importância 
dos domínios privados e do quotidiano juvenil". Nas últimas duas décadas, muitos jovens passaram a articular-se nos chamados coletivos e por coletivos entendemos o que Brasil (2015, p. 15) conceitualiza como "um grupo de pessoas que exploram interesses em comum e articulam ações de forma estratégica, fazendo circular informação, cultura, economia, política, saberes e práticas". A suas formas de organização são voluntárias, temáticas, às vezes efêmeras, e não necessariamente formais.

Segundo Maia (2013, p. 62), o fenômeno dos agrupamentos das juventudes em coletivos "trata-se, de um lado, do reconhecimento, hoje consensual, de novos agenciamentos capazes de fomentar a ação coletiva juvenil para além dos espaços consagrados da política institucional partidária ou do movimento estudantil.". A autora aponta a tendência vigente nas juventudes em buscar espaços menos burocratizados e que enfatizem a criatividade em suas modalidades de ação política, contestando modelos de organização como os Conselhos Tutelares (MAIA, 2013).

Fuentes (2007), ao estudar coletivos juvenis no Chile, enfatiza a preferência dos jovens inseridos em coletivos por um caráter autogestionado em virtude de uma desconfiança crescente no sistema tradicional da política representativa. A autora sintetiza este processo:

"Las palabras de los jóvenes corroboran la argumentación de Reguillo (2000), quien sostiene que en las últimas décadas las juventudes latinoamericanas han ido buscando y encontrando nuevas formas de organización que se separan de lo «tradicional». Para esta autora (2000:72), una de las cuestiones básicas que permiten la distinción de las nuevas formas organizativas juveniles respecto de los espacios tradicionales, es el carácter autogestionado de las expresiones juveniles, en donde «la responsabilidad recae sobre el propio colectivo sin la intermediación o dirección de adultos o instituciones formales»" (FUENTES, 2007, p. 47).

Além das considerações feitas acima, Maia (2013) percebe como as motivações políticas dos jovens ultrapassam um território que antes se restringia ao conflito de classes, este apoiado em epistemologias marxistas; a autora nota a presença de uma dinâmica social específica no funcionamento dos coletivos, que se articulam em meio a questões culturais e sobretudo identitárias. Nesse contexto, cabe mencionar o que Reguillo (2003) entende por uma culturalização da política: enxergar e fazer política a partir da cultura. Fuentes (2007), utilizando-se de tal conceito, afirma que a culturalização da política é um fenômeno que pode ser visto em diversas práticas dos coletivos juvenis.

Nas palavras de Fuentes (2007, p. 48), "es este fenómeno el que se observa en las prácticas de los colectivos juveniles analizados, los que a través de la música, talleres artísticos, festivales, ferias de la cultura, etc., transmiten mensajes que son abiertamente políticos.". Ao associar a ideia de culturalização da política com conceitos já discutidos no presente trabalho - a exemplo de questões como a micropolítica ou as life politics (CAMPOS; SARROUY, 2020), que evidenciam a interação das pautas políticas com as culturas juvenis - é 
possível delinear com mais precisão os contextos de insurgência dos coletivos na arena política, contestando também as formas convencionais e verticalizadas de se fazer política.

Tendo em vista as questões levantadas acerca do associativismo juvenil, é imprescindível mencionar as novas formas de organização online que operam nesse contexto. As relações entre as juventudes e o universo digital são discutidas por uma série de autores, cabendo mencionar Gohn (2013), Feixa (2014), Canclini (2012), Castells (2012), Pleyers (2013) e Marcon (2019). Feixa (2014), na obra “De la generación @ a la \# generación: la juventud en la era digital", discorre sobre o que considera as duas gerações mencionadas no título: uma refere-se aos jovens que vivenciaram os primeiros passos das tecnologias digitais e outra que se refere aos jovens que vivenciaram uma "generalização" destas tecnologias em suas vidas.

Marcon (2016) contextualiza a abordagem de Feixa (2014):

"Se o @ simboliza a emergência de uma referência de comportamento cibercultural, que a partir de meados dos anos noventa passa a fazer parte da vida dos jovens em suas atividades de estudo, de trabalho e de lazer através dos conteúdos de produção digital, lógicas de produção e consumo desmaterializadas, como uso de microcomputadores; o \# significa a expansão para o uso social das conexões em rede, o uso da internet em dispositivos móveis, a intensidade dos fluxos e a lógica da instantaneidade do compartilhamento social e das referências temáticas dispersas numa web global" (MARCON, 2016, p. 333).

Nesse sentido, o fazer político também passa a tomar diferentes proporções num cenário de constante difusão da comunicação via web. Cabe mencionar as formas de ativismo juvenil pós-2010, presentes nos episódios conhecidos como Primavera Árabe, movimento Occupy Wall Street, movimento dos Indignados na Espanha, as manifestações de junho de 2013 no Brasil e outras manifestações que se seguiram. Gohn (2013) aponta que a estruturação de marchas, atos e protestos por meio de redes sociais virtuais é um grande diferencial entre as formas de participação política das juventudes contemporâneas frente às de outros momentos históricos. A autora percebe que o uso de recursos de comunicação como computadores e smartphones aliam-se à ocupação do espaço público, como visto no Brasil no ciclo de protestos de junho de 2013 e nas manifestações que o sucederam, sendo muitas delas organizadas virtualmente.

Pleyers (2013), ao notar essa conexão entre práticas online e offline, aponta que é preciso superar a dicotomia entre "mundo real" e "mundo virtual" a fim de compreender a dimensão dessas novas formas de organização política, visto que, para o autor, ambas são complementares. Para Pleyers (2013), é pertinente observar que "as subjetividades políticas e os atores dos movimentos sociais de hoje surgem da articulação e fertilização recíproca entre a vida cotidiana e a política, entre o mundo da internet e o das praças públicas, entre as redes sociais e o convívio dos espaços militantes" (PLEYERS, 2013, p. 94). 
Já Castells (2012) conceitualiza a intersecção entre o que acontece no ciberespaço e no espaço urbano como um terceiro espaço, um "espaço de autonomia" no contexto dos movimentos sociais. O autor discute a adoção deste termo:

\begin{abstract}
"Este híbrido de ciberespacio y espacio urbano constituye un tercer espacio que yo llamo el espacio de autonomía. El motivo es que la autonomia sólo se puede garantizar mediante la capacidad de organización en el espacio de libertad de las redes de comunicacion, pero al mismo tiémpo únicamente se puede ejercer como fuerza transformadora si se desafía el orden institucional disciplinario recuperando el espacio de la ciudad para sus ciudadanos. La autonomia sin desafío se convierte en retirada. El desafío sin una base permanente de autonomia en el espacio de los flujos equivale a un acitvismo descontinuo. El espacio de autonomía es la nueva forma espacial de los movimientos sociales en red" (CASTELLS, 2012, p. 213).
\end{abstract}

Dessa maneira, é possível perceber uma série de discussões que já levantam um redimensionamento nas formas de organização e atividade dos movimentos sociais, bem como suscitam novas reflexões acerca do que se entende por espaço público; principalmente quando relacionados às juventudes da contemporaneidade, que representam gerações dotadas de um contato íntimo com recursos digitais. As realidades material e virtual mesclam-se, e esta constatação é de suma importância para compreender as formas de participação política de coletivos - já que estes são formas de organização política que ganham visibilidade neste contexto - que têm como público as juventudes.

A difusão das reivindicações juvenis no modelo organizacional de coletivos também pode ser observada em Sergipe, como visto por Santos (2017) e Fusaro (2018), ao estudar as formas de ação política do Coletivo Debaixo. Santos (2017) investiga o que entende pela gramática política deste coletivo, aprofundando-se nas lógicas de articulação política das juventudes que o compõem, e conclui que o Coletivo Debaixo representa movimentos de reivindicação política juvenil subsequentes ao ciclo de protestos de junho de 2013. Cabe destacar a realização do evento Sarau Debaixo, realizado no viaduto do D.I.A, que condensou as formas de contestação política do coletivo aliadas a recursos estéticos por meio da ocupação do espaço público. Também é importante mencionar que Santos (2017) aponta para uma pluralidade de eventos nesse formato realizados pelas juventudes em outros municípios do estado, como o Sarau do Calçadão e o Sarau do Coreto em Itabaiana, o Sarau da Caixa D'água em Lagarto, e o Sarau do Alecrim em Estância (SANTOS, 2017).

Já Fusaro (2018), ao estudar as ocupações culturais na cidade de Aracaju, estende-se sobre três eventos responsáveis por concentrar a juventude nos espaços públicos da capital de forma independente: Sarau Debaixo, Clandestino e Ensaio Aberto, sendo todos entendidos pela autora como movimentos de reivindicação política permeados pela produção artística e pelo entretenimento.

Assim como o Sarau Debaixo, o Ensaio Aberto também foi pensado e realizado por meio de um coletivo de jovens (o Coletivo Ensaio Aberto), e, como menciona a autora, ocupou um papel político diante do público ao debater questões sociais em algumas das 
edições do Ensaio Aberto, realizado no Parque dos Cajueiros, "trazendo professores universitários, líderes de movimentos sociais e outras personalidades referências para discutir alguma temática específica, a exemplo de disparidade de gênero, desigualdade social e do cenário político do país" (FUSARO, 2018, p. 41). É pertinente enfatizar que atualmente ambos os coletivos Debaixo e Ensaio Aberto não se encontram em atividade, o que demonstra certa efemeridade presente nestas formas políticas de organização. Além dos coletivos mencionados acima, destacam-se outros que adotam a cultura como princípio aglutinador de suas práticas envolvendo as juventudes, que serão enumerados a seguir.

Abaixo trazemos um quadro demonstrativo com alguns dos coletivos juvenis em atividade na grande Aracaju. O quadro foi construído a partir de um mapeamento realizado por meio de pesquisa exploratória na internet, da literatura de pesquisas sobre coletivos de jovens que atuam com a cultura na grande Aracaju, do contato com representantes do CONEJUVE ${ }^{7}$ e com representantes dos próprios coletivos arrolados. É pertinente levantar reflexões acerca deste mapeamento: devido à fluidez com que se compõem muitos dos coletivos, pois muitos existem apenas por um curto espaço de tempo, manifestando-se muitas vezes de maneira informal.

Pelas particularidades apontadas acima, não seria possível darmos conta de uma lista completa de tais coletivos ativos em Sergipe ${ }^{8}$ e utilizamos o quadro abaixo a título de exemplo para as finalidades da análise neste artigo. Assim sendo, abaixo procuramos elaborar uma relação com informações mínimas como o nome, o ano de criação, a localidade de atuação e em como tais coletivos se definem em termos de enfoque ou pauta. O objetivo é demostrar a diversidade das especificidades temáticas de seus enfoques para além do próprio entendimento de que são coletivos juvenis. Apesar de a maioria deles terem se constituído na última década, há alguns poucos coletivos consolidados há mais tempo.

Nesse sentido, arrolamos coletivos que apresentam ou apresentaram um alcance considerável em suas iniciativas e reivindicações, viabilizando uma análise das dimensões políticas dessas formas de associativismo. Outra observação a ser feita é de que, ainda que

\footnotetext{
${ }^{7}$ O Conselho Estadual da Juventude de Sergipe (CONEJUVE) é o principal órgão de representação juvenil do estado. Foi fundado em 2014, a partir da Lei 7.815, e é composto por 28 conselheiros titulares e seus respectivos suplentes, representados pelo poder público e pela sociedade civil.

${ }^{8}$ Os dados que constam no quadro demonstrativo foram coletados, como mencionado, em uma pesquisa exploratória na internet. Esta pesquisa se deu por meio do acesso às páginas dos coletivos nas redes sociais Facebook e Instagram, e em alguns momentos por meio do acesso a blogs dos coletivos. Na maioria das vezes, o enfoque e o ano de fundação de cada coletivo constavam em seus perfis nas redes. Em outros casos, foi possível encontrar postagens, cujo intuito era apresentar os coletivos, nas quais tais dados estavam presentes. Nesse sentido, é interessante notar que as redes sociais são meios relevantes de divulgação das premissas e atividades de cada coletivo. Outra fonte de informação sobre os coletivos partiu do levantamento da recente bibliografia sobre o tema em Sergipe, conforme as citações acima.
} 
todos os coletivos mencionados tenham a cultura como interface na condução de suas iniciativas, eles podem atuar em diversas frentes, como expomos a seguir:

Quadro 1- Demonstrativo de Coletivos na Grande Aracaju

\begin{tabular}{|c|c|c|c|}
\hline $\begin{array}{l}\text { NOME DO } \\
\text { COLETIVO }\end{array}$ & $\begin{array}{l}\text { DATA DA } \\
\text { FUNDAÇÃO }\end{array}$ & LOCALIDADE & ENFOQUE \\
\hline $\begin{array}{l}\text { Coletivo ALPV - } \\
\text { Aliados Pelo Verso }\end{array}$ & 2001 & Агасајu & Hip-hop \\
\hline $\begin{array}{l}\text { Coletivo Nação Hip- } \\
\text { hop Brasil }\end{array}$ & 2005 & Агасајu & Hip-hop \\
\hline BC Movimento & 2010 & Barra dos Coqueiros & $\begin{array}{l}\text { Educação, arte e } \\
\text { cultura }\end{array}$ \\
\hline $\begin{array}{l}\text { Projeto Pescando } \\
\text { Memórias }\end{array}$ & 2012 & $\begin{array}{l}\text { Nossa Senhora do } \\
\text { Socorro }\end{array}$ & Cultura popular \\
\hline $\begin{array}{l}\text { Coletivo de } \\
\text { Mulheres de Aracaju }\end{array}$ & 2012 & Aгасаju & Movimento feminista \\
\hline Coletivo Quilombo & 2012 & Агасајu & $\begin{array}{l}\text { Movimento negro e } \\
\text { feminista }\end{array}$ \\
\hline $\begin{array}{l}\text { Coletivo Socorreria } \\
\text { Arte Urbana }\end{array}$ & 2014 & $\begin{array}{l}\text { Nossa Senhora do } \\
\text { Socorro }\end{array}$ & $\begin{array}{l}\text { Arte de rua (ênfase no } \\
\text { grafitti) }\end{array}$ \\
\hline Coletivo MUDE & 2016 & Агасајu & Educação \\
\hline Coletivo Entre Becos & 2017 & Aracaju & $\begin{array}{l}\text { Produção audiovisual e } \\
\text { eventos culturais }\end{array}$ \\
\hline Coletivo Inferninho & 2017 & Grande Aracaju & $\begin{array}{l}\text { Produção de eventos } \\
\text { culturais }\end{array}$ \\
\hline Coletivo Bueiro & 2018 & Grande Aracaju & Hip-hop \\
\hline $\begin{array}{l}\text { Coletivo Camaleão } \\
\text { Urbano }\end{array}$ & 2018 & Агасајu & $\begin{array}{l}\text { Intervenção urbana, } \\
\text { causas ambientais e } \\
\text { arte }\end{array}$ \\
\hline $\begin{array}{l}\text { Coletivo Negro } \\
\text { Beatriz Nascimento }\end{array}$ & 2018 & São Cristóvão & Movimento negro \\
\hline Coletivo Exp & 2019 & Aracaju & Arte \\
\hline Serigy Coletivo & 2019 & Aгасајu & $\begin{array}{l}\text { Música, poesia e artes } \\
\text { visuais }\end{array}$ \\
\hline Poesia Marginal & 2019 & Агасајч & $\begin{array}{l}\text { Eventos (batalhas de } \\
\text { poesia/slam) }\end{array}$ \\
\hline $\begin{array}{l}\text { Movimento Tudo } \\
\text { para Todos }\end{array}$ & 2019 & Aгасајu & Ações por moradia \\
\hline Coletivo Yibambe & 2020 & Aracaju & Movimento negro \\
\hline $\begin{array}{l}\text { Coletivo Mulheres } \\
\text { que Não Calam }\end{array}$ & 2020 & Aгасајu & Movimento feminista \\
\hline
\end{tabular}

Durante o mapeamento dos coletivos, foi possível perceber uma diversidade de grupos que apresentam um enfoque em práticas criativas e artísticas. Nesse contexto, faz-se necessário evidenciar o hip-hop enquanto movimento presente nas realidades de muitos jovens sergipanos, sobretudo os que apresentam algum tipo de vulnerabilidade social (em especial negros e da periferia). Marcon e Souza Filho (2013), Freitas (2018) e Silva (2020) já discutiram sobre a importância da presença do hip-hop na reivindicação de direitos das juventudes em Sergipe, movimento este que condensa música, dança e outros recursos 
artísticos também em prol do engajamento juvenil. Ao realizarmos este levantamento, pudemos notar que vários dos coletivos se associam a este segmento de expressão cultural e se encontram em atividade, como é o caso do Aliados Pelo Verso - ALPV, da Nação Hip-hop Brasil, do BC Movimento e do Coletivo Bueiro. Também é pertinente citar coletivos em atividade e envolvidos em batalhas de poesias - conhecidas por slams - que reivindicam questões identitárias e políticas, a exemplo dos coletivos Poesia Marginal e Entre Becos.

No contexto do hip-hop, por vezes os coletivos são também entendidos como posses, como mencionamos anteriormente. Marcon e Souza Filho (2013) percebem a dimensão política de tais grupos e discorrem que

\begin{abstract}
"A posse representa a articulação entre a atuação estética e a organização política de um grupo de artistas e ativistas do rap, do graffiti e da dança de rua mediados fortemente pela ideia que eles fazem da relação entre movimento cultural e consciência política, bem como na forma com que tal referência é mobilizada" (MARCON; SOUZA FILHO, 2013, p. 510).
\end{abstract}

Além do hip-hop, é possível observar no quadro acima vários movimentos relacionados a pautas antirracistas, feministas, ambientalistas e em prol da redistribuição de moradias e da arte de rua. É pertinente observar que há pontos que são comuns a todos os coletivos - suas características de organização e associativismo - mas também os pontos específicos de cada coletivo, em termos de áreas temáticas. Esse fenômeno pode ser associado à segmentação da participação política das juventudes mencionada por Augusto (2008), que apresentam uma tendência em responder a pautas mais localizadas e menos vinculadas à política convencional. Campos e Sarrouy (2020, p. 23) reiteram esta questão quando afirmam que "o início do milênio dá origem a uma fase em que se destaca a individualização e fluidez da participação política dos jovens orientada para causas específicas (cause-oriented engagement), que acompanha um desinteresse pela política formal e os seus atores".

Mesquita $(2003 ;$ 2008) menciona o importante papel que os coletivos de cultura assumiram, particularmente, enquanto atuação política das juventudes. Рara o autor, os coletivos voltados à cultura estabeleceram laços de proximidade com entidades estudantis, que desde os anos sessenta tiveram um protagonismo político significativo, e situa tais coletivos como "herdeiros de uma tradição do movimento estudantil que alia cultura à participação, arte à política" (MESQUITA, 2008, p. 204). Nesse sentido, Mesquita (2008) também enfatiza a informalidade como um dos critérios para um redimensionamento da prática política estudantil.

Segundo o autor,

"Todos estes elementos baseados nas micro-relações, na informalidade, são essenciais na construção de identidades, no fortalecimento dos grupos, na formulação de projetos de ação para o futuro. O corte identitário passa aqui através destas relações: da pessoalidade, do lazer, das relações construídas através dos signos que misturam elementos da identidade tanto estudantil quanto juvenil, etc.; diferente da dinâmica e 
lógica tradicional do movimento estudantil - também legítima - que passa por outras vias e espaços identitários e que produz outras regras e lógicas na ação militante" (MESQUITA, 2008, p. 194).

Tendo em vista as observações feitas até aqui, destacamos a diversidade de iniciativas voltadas às juventudes no âmbito da cultura e percebemos a relevância dos coletivos como novas formas de engajamento político dos jovens em Sergipe. Essas juventudes se organizam a partir dos espaços públicos da rua e da internet, ou seja, dos espaços de vizinhança, escolarização, de lazer, de trabalho e de comunicação, entre outros. Também analisamos aqui como os coletivos juvenis se inserem enquanto novos recursos de participação política na contemporaneidade, como discutem Augusto (2008), Campos e Sarrouy (2020), Gohn (2008), Reguillo (2003) e outros. Além de apontarmos o caráter autogestionado destas formas de organização e sua dimensão criativa, destacamos que eles associam suas formas de atuação política a recursos estéticos, como a arte, e diluem-se em uma diversidade de pautas (como movimento negro, movimento feminista, causas ambientais etc.), sendo este um retrato do "engajamento orientado por causas", como mencionado por Campos e Sarrouy (2020).

\section{CONSIDERAÇÕES FINAIS}

Partindo das observações e argumentações feitas acima, um ponto central a ser enfatizado se dá na escolha por parte destes jovens e dos coletivos de que o campo da expressão e da atuação cultural é um campo político significativo de transformação. A escola, a rua e a internet são os lugares a partir dos quais as juventudes vêm construindo seus entendimentos de mundo, incluindo o aprendizado sobre as formas de fazer política, de se auto-organizar, de reivindicar, de protestar e de atuar frente a diferentes demandas e causas que os afligem, associando-se ou não, em algum momento, a partido políticos, mas fundamentalmente elegendo como prioridade as formas de atuação e representação política mais diretas. Também pudemos constatar que em ambos os casos, são formas de socialização, de aprendizado e de comunicação com características geracionais marcadas fortemente pela compreensão etária mais alargada do ser jovem. Estas questões têm consequências na relação entre a institucionalização e o alcance efetivo da política pública para as juventudes, e o envolvimento e a forma com que tais coletivos as reivindicam, criando um descompasso entre normas e práticas, principalmente quando os atores não se percebem contemplados pelas práticas dos gestores e técnicos da política pública.

Neste sentido, é necessário, também, problematizar a disponibilidade e alcance das políticas públicas para além do texto das normas e da burocratização voltadas às juventudes seja no caso de Sergipe ou no Brasil. O engajamento das juventudes em uma participação política fora dos limites da formalização se dá devido a um decréscimo da confiança destes 
jovens na política institucionalizada, mesmo diante do surgimento dos aparatos legais para implantação de tais políticas. Entretanto, além deste fator, cabe mencionar que não há um diálogo efetivo, próximo e constante entre o poder público e as juventudes, mesmo quando regulamentados os conselhos estaduais ou municipais de juventude ou instituídas as secretarias de governo correlatas. Como depreendemos das entrevistas com os gestores da política pública em Sergipe, não existem formas de comunicação e publicização amplas e eficazes da legislação, das políticas e da própria possibilidade de representação e participação dos jovens em tais processos. O que cria um descompasso entre a política pública institucional e a atuação política dos coletivos, como vimos.

Com base nas discussões trazidas no presente artigo, é importante levantar o que entendemos por uma política pública verdadeiramente inclusiva no âmbito das juventudes: uma política feita para os jovens com a participação integral deles nos processos de construção e implementação de tais políticas, contemplando suas diversas formas de manifestação política e cultural. A participação dos coletivos juvenis nesse contexto é fundamental, visto que os mesmos já se organizam ativamente enquanto mecanismos de contestação política e de reivindicação de direitos; já atuam e servem como modelo de fazer política e de demandas dos jovens de distintos contextos socioeconômicos. Dessa maneira, o Estado garantiria uma presença efetiva dos jovens na construção de uma política pública de/para/com juventudes que os contemple enquanto cidadãos. O que deve ser construído com ampla comunicação e diálogo, representação das juventudes em termos de diversidade social, planejamento coletivo, recursos humanos e orçamento.

Caberia ao poder público, portanto, abordar as juventudes para compreender: o que estes jovens entendem por política pública? Quais áreas são consideradas urgentes por eles? Quais as demandas e quais as formas de construir soluções coletivas e representativas? Nesse sentido, é pertinente frisar a necessidade da elaboração e da execução de políticas públicas que contemplem a juventude enquanto categoria social plural e em suas demandas multidimensionais mais ou menos pragmáticas. As políticas públicas voltadas aos jovens apresentariam maior eficiência se dotadas de caráter transversal, contando com a presença tanto de gestores públicos, de pesquisadores, quanto de representantes de coletivos das juventudes. No estado de Sergipe, tais políticas se mostram dispersas, insuficientes e em frágil consonância com as demandas daqueles que deveriam ser seus protagonistas.

\section{REFERÊNCIAS}

ABRAM0, Helena Wendel. Considerações sobre a tematização social da juventude no Brasil. Revista Brasileira de Educação, p. 12, 1997. 
AUGUST0, Nuno Miguel. A juventude e a(s) política(s): Desinstitucionalização e individualização. Revista Crítica de Ciências Sociais, n. 81, p. 155-177, 2008.

BHOGOSSIAN, C; MINAYO, M. Revisão sistemática sobre juventude e participação nos últimos 10 anos. Saúde Soc. São Paulo, v. 18, n. 3, p. 411-423, 2009.

BRASIL. Lei No 11.129, de 30 de junho de 2005. Institui o Programa Nacional de Inclusão de Jovens ProJovem; cria o Conselho Nacional da Juventude - CNJ e a Secretaria Nacional de Juventude; altera as Leis $n^{0}$ s 10.683, de 28 de maio de 2003, e 10.429, de 24 de abril de 2002; e dá outras providências. Brasília: Casa Civil, 2005.

BRASIL. Estatuto da juventude: atos internacionais e normas correlatas. Brasília: Senado Federal, Secretaria de Editoração e Publicações, Coordenação de Edições Técnicas, 2013.

BRASIL. Ministério da Mulher, da Família e dos Direitos Humanos. Conselho Nacional de Juventude. Brasília, 2020.

BRASIL, Wener da Silva. 0 Coletivo Fora do Eixo: Juventude organizada, produção, circulação e consumo cultural. Dissertação (Mestrado em Sociologia). Universidade Federal de Sergipe, 2015.

CAMPOS, Ricardo; SARROUY, Alix. Juventude, Criatividade e Agência Política. TOM0, n. 37, p. 17-46, 2020.

CANCLINI, Néstor García (0rg.). Jóvenes, culturas urbanas y redes digitales: prácticas emergentes en las artes, las editoriales y la música. Primera edición. Barcelona: Editorial Ariel, 2012.

CASTELLS, Manuel. Redes de indignación y esperanza: los movimientos sociales en la era de Internet. Madrid: Alianza Editorial, 2012.

CAVALCANTE, Itanamara. Juventude em pauta: 0 processo de construção da política pública de juventude em Sergipe. Dissertação (Mestrado em Serviço Social). Universidade Federal de Pernambuco, 2010.

CHARLOT, Bernard. Juventudes Sergipanas: relatório de pesquisa. Aracaju: Editora J. Andrade, 2006.

DELGAD0, Manuel. Artivismo y pospolítica. Sobre la estetización de las luchas sociales en contextos urbanos. Quaderns-e, Institut Català d'Antropologia, v. 18, n. 2, p. 68-80, 2013.

DIÓGENES, Glória. Juventude, exclusão e a construção de políticas públicas: estratégias e táticas. In: MENDONÇA FILHO, M.; NOBRE, M. T. (Org.). Política e afetividade: narrativas e trajetórias de pesquisa. Salvador: EDUFBA; São Cristóvão: EDUFES, 2009. p. 271-288.

DIÓGENES, Glória. Cidade, arte e criação social: novos diagramas de culturas juvenis da periferia. In: Estudos avançados. v. 34 ก. 99, 2020.

FEDERAL, Governo. Estatuto da Criança e do Adolescente. Lei federal, v. 8, 1990.

FEIXA, Carles. De la generación @ a la \# generación: la juventud en la era digital. Barcelona, NED, 2014. 
FREITAS, M. Jovens mulheres, hip-hop, estilo de vida e feminismo. Dissertação - Mestrado em Sociologia. Universidade Federal de Sergipe, 2018.

FUENTES, Katia Valenzuela. Colectivos juveniles: ¿inmadurez política 0 afirmación de otras políticas posibles?, Ultima década, v. 15, n. 26, p. 31-52, 2007.

FUSARO, Luana. Juventude e ocupações culturais em Aracaju: da arte ao protesto. Dissertação Mestrado em Antropologia. Universidade Federal de Sergipe, 2018.

GALVÃO, L. Juventudes e políticas públicas na Grande Aracaju: os coletivos MUDE e Socorreria Arte Urbana. Monografia - Graduação em Ciências Sociais, Universidade Federal de Sergipe, 2021.

GALVÃO, L. SANTANA, J. OLIVEIRA, A. Perspectiva Institucional dos Sentidos das Juventudes nas Políticas Públicas em Sergipe: uma análise a partir das representações de juventude pelos gestores públicos. In: Anais do III Seminário Nacional de Sociologia da UFS. v. 3, p. 1-15, 2020.

GOHN, Maria da Glória. Abordagens teóricas no estudo dos movimentos sociais na américa latina, Caderno CRH, v. 21, n. 54, p. 439-455, 2008.

Os Jovens e as praças dos indignados: territórios de cidadania. In: Revista Brasileira de Sociologia. v. 01, n. 02. jul/dez. 2013.

HONWANA, Alcinda. Juventude, Waithood e Protestos Sociais em África. In: BRITO, Luís de et al. (0rg.) Desafios para Moçambique 2014. Maputo: Instituto de Estudos Sociais e Económicos, 2014. p. 399-412.

MAIA, Gretha Leite. A Juventude e os Coletivos: como se articulam novas formas de expressão política, Revista Eletrônica do Curso de Direito da UFSM, v. 8, n. 1, p. 58, 2013.

MARCON, Frank; FILHO, Florival de Souza, Estilo de vida e atuação política de jovens do hip-hop em Sergipe. Revista de Antropologia, v. 56, p. 36, 2013.

MARCON, Frank. 0 kuduro como expressão da juventude em Portugal: estilos de vida e processos de identificação. Sociedade e Estado, v. 28, n. 1, p. 75-90, 2013.

MARCON, Frank. Agências estetizadas, geração digital, ativismos e protestos no Brasil, Ponto Urbe, n. 23, p. 1-20, 2018.

Geração e juventude na era digital. Política \& Sociedade, v. 15, n. 32, p. 332, 2016.

MARCON, Frank; NORONHA, D. (Org.) Juventudes e movimentos. Aracaju: Criação, 2018.

MARCON, Frank; NORONHA, D. (Org.) Diálogos com os estudos culturais: representações, identidades e poder. São Cristóvão: Editora UFS, 2020.

MESQUITA, Marcos Ribeiro. Movimento estudantil brasileiro: Práticas militantes na ótica dos Novos Movimentos Sociais. Revista Crítica de Ciências Sociais, n. 66, p. 117-149, 2003.

Cultura e política: A experiência dos coletivos de cultura no movimento estudantil. Revista Crítica de Ciências Sociais, n. 81, p. 179-207, 2008. 
NETO, Mateus Antônio. Juventudes e estilos de vida: sociabilidades no bairro Siqueira Campos. Dissertação - Mestrado em Antropologia, Universidade Federal de Sergipe, 2012.

OLIVEIRA, T. 0 rock e o sertão: juventude, consumo e estilo de vida em Sergipe. Dissertação (Mestrado em Antropologia). Universidade Federal de Sergipe. 2013.

ORTNER, S. Poder e projetos: reflexões sobre a agência. In: GROSSI, Miriam Pillar; ECKERT, Cornélia; FRY, Peter Henry (0rg.).Conferências e diálogos: saberes e práticas antropológicas. $25^{a}$ Reunião Brasileira de Antropologia: Goiânia, 2006. Blumenau: Nova Letra, 2007. p. 45-80.

PLEYERS, Geoffrey. Ativismo das ruas e on-line dos movimentos pós-2011. Lutas Sociais, São Paulo, v. 17 ก. 31, p. 87-96, 2013.

REGUILLO, R. Ciudadanías Juveniles en América Latina. Ultima década, v. 11, n. 19, p. 11-30, 2003.

SANTOS, Célio José dos. Os Saraus de Poesia - Cultura, Política e Juventude em Movimento. Crítica e Sociedade: revista de cultura política. v. 9, n. 2, p. 209-230, 2019.

SANTOS, J. "As manifestações de junho de 2013 pra gente não acabou": um estudo sobre as formas de contestação no Coletivo Debaixo em Aracaju. Dissertação - Mestrado em Sociologia, Universidade Federal de Sergipe, 2017.

SILVA, A. Juventudes, Hip-hop e Políticas Públicas na Grande Aracaju. Dissertação - Mestrado em Sociologia, Universidade Federal de Sergipe, 2020.

SILVA, W. A galera da catedral: representações de um estilo de vida underground e lógicas de apropriação do espaço urbano. Dissertação de Mestrado - Mestrado em Sociologia, Universidade Federal de Sergipe, 2011.

SPOSITO, Marília Pontes; CARRANO, Paulo César Rodrigues. Juventude e políticas públicas no Brasil. Revista Brasileira de Educação, n. 24, p. 16-39, 2003.

TOMMASI; L. CORROCHANO, M. Do qualificar ao empreender: políticas de trabalho para jovens no Brasil. Estudos avançados. v. 34, n. 99, p. 353-372, 2020.

UN, General Assembly. International Youth Year: Participation, Development, Peace. In: Resolutions and decisions adopted by the General Assembly during its 40th session. New York: UN, 25 Nov. 1985. 